\title{
Anterior Cervical Discectomy, Corpectomy with MRI Compatible Titanium Plate and Screw Fixation Under Neurophysiological Monitoring, Experience of 27 Years
}

\section{PK Upadhyay ${ }^{1 *}$, G Tiwary ${ }^{2}$, K upadhyay ${ }^{3}$ and Kritika $U^{4}$}

${ }^{1}$ Head of Neurosurgery Department, Institute of Human Behavior and Allied

Sciences Hospital, Delhi, India

${ }^{2}$ Director Laboratory Sciences, India

${ }^{3} \mathrm{MBBS}$ Fellow, JSSMC, India

${ }^{4} M A M C$, India

*Corresponding Author: PK Upadhyay, Head of Neurosurgery Department, Institute of Human Behavior and Allied Sciences Hospital, Delhi, India.
Received: December 08, 2021

Published: December 29, 2021

(C) All rights are reserved by PK Upadhyay., et al.

\begin{abstract}
115 cases operated by the senior author in 27 years utilizing neurophysiological monitoring, using anterior cervical discectomy and corpectomy and immediate fixation using MRI compatible titanium screw and plate under Neurophysiological monitoring of somato sensory evoked potential and motor evoked potential, which helped immensely in preventing damage to neural structure and improving results, both for spinal surgeon and the patients.

The results evaluated and review of literature done.

Keywords: Anterior Cervical Discectomy; Corpectomy; MRI Compatible; Titanium Plate and Screw; Neurophysiological Monitoring
\end{abstract}

\section{Introduction}

Anterior cervical plating by MRI compatible plate and screw device under Neurophysiological monitoring is very useful and safe procedure for patient and convenient for Neurosurgeons. It also maintains alignment and prevents graft extrusion. It also helps in preventing late deformities and also removes the need for a secondary posterior cervical procedure [1].

Procedure under Neurophysiologocal monitoring reduces chances of neural damage and smooth procedure for Neurosurgeon.

Anterior Approach to cervical spine and fusion was first introduced by Robinson and Smith (1958) [2] and latter by Clowards (1958) [3].

This approach is useful for single or two level disc prolapsed causing spondylotic radiculopathy, myelopathy or myeloradiculop- athy or management of cervical spinal instability following trauma, multiple discectomy or corpectomy, cervical spondylosis or sublaxation due to pott's spine.

Internal fixation and stabilization has high fusion rate and nil graft displacement by use of anterior casper plate fixation [4], stabilization with anterior Asif plate fusion technique in acute cervical trauma has also been emphasized [5].

These are not MRI compatible and needed C-arm for putting screws and plate adequately, they also needed bi cortical penetration, which resulted in more time consuming and more complications.

\section{Material and Methods}

From 1994 till 2021, the senior author treated 115 cases of cervical instability with monocortical locking screw and plate device, in various hospitals. 
Indications for the procedure were

- Trauma having sublaxation and dislocations (60 cases)

- Cervical spondylosis (multiple discectomy and corpectomy (45 cases)

- $\quad$ Step deformity and sublaxation due to healed pott's spine or osteomyelitis (8 cases)

- $\quad$ Cases of Potts spine where the grafts were displaced from previous surgery (02cases).

There were 75 males and 40 were female patient.

Ages varied from 15 years to 75 years. 87 case were in $3^{\text {rd }}$ and $4^{\text {rth }}$ decade 8 cases were in $2^{\text {nd }}$ decade, and 17 cases in $5^{\text {th }}$ decade, 3 cases in $6^{\text {th }}$ and $7^{\text {th }}$ decade.

MRI picture of few cases are shown in picture 1-3.

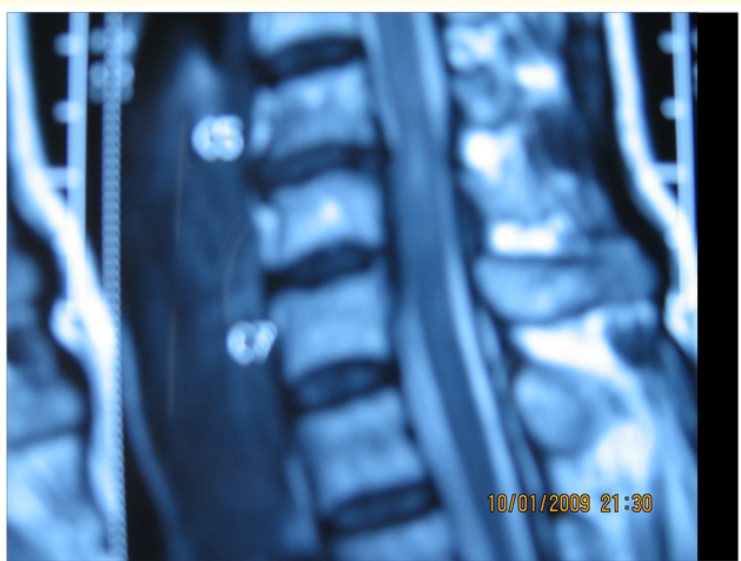

Picture 1: Pre operative MRI.

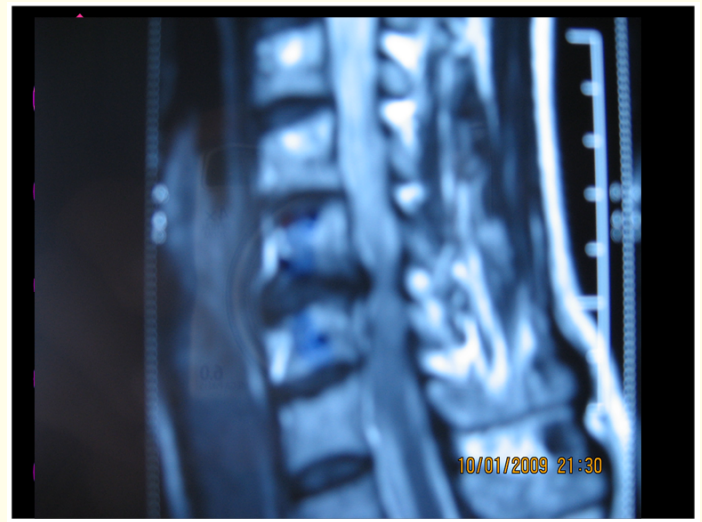

Picture 2: Preoperative MRI.

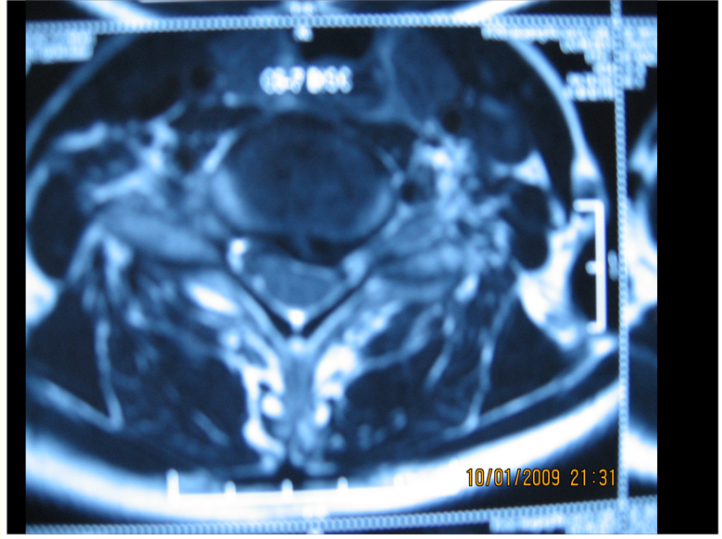

Picture 3: Pre operative MRI.

The cervical locking plate was designed to stabilize the spine in one stage with decompression to obtain maximum construct rigidity using relatively simple instruments. We used plates made of Pure Titanium in $2 \mathrm{~mm}$ thickness in 15 lengths from $16 \mathrm{~mm}$ to 90 mm depending upon requirement.

The plates have a pair of cranial caudal holes to accommodate cancellous anchor screw and a many intermediate holes in middle to anchor the graft.

Post operative $\mathrm{x}$-ray is shown in picture 5,6 .

\section{Neurophysiological monitoring (IONPM)}

Intraoperative neurophysiological monitoring (IOM) in spinal surgery to reduce the incidence of postoperative neurological complications., et al. neurological level. many techniques are available and motor and somatosensory evoked potentials are thought to be essential for better results of IONPM. Spinal cord evoked potentials (SEP) are observed and recorded over cord. Electrical stimulation is given on the dorsal of spinal cord by an epidural electrode. Somatosensory evoked potentials(SSEP) provides the functional continuity of sensory pathways. That's so from the terminal nerve through the dorsal column going up till the sensory cortex.

Motor evoked potentials (MEPs) consist of spinal, neuralc and musclular MEPs. MEPs performs selective and specific examination of the working intactness of descending motor pathways, starting from the motor cortex to the terminal muscles. Neurological surgeons must understand the monitoring techniques and read monitoring records properly to understand use IONPM for the proper decision making during the neurosurgery for safe spinal neurosurgery and better surgical results. 
Anterior Cervical Discectomy, Corpectomy with MRI Compatible Titanium Plate and Screw Fixation Under Neurophysiological Monitoring, Experience of 27 Years

\section{Somatosensory evoked potentials (SSEP)}

SEPs were first utilized in the 1970s to assess and monitor the spinal cord function during spinal surgery for scoliosis treatment. After stimulating terminal nerves, SEPs are measured both from the spinal cord, epidural electrode and/or simultaneously from the sensory cortex of the brain [6]. Normally, the posterior tibial nerve is used for taking ssep traces.

Used data are stimulation, $0.2 \mathrm{~ms}$ duration; at, $-3 \mathrm{~Hz}$ frequency; with intensity $-25 \mathrm{~mA}$. This is Given for one minute and averaging gives SSEP result [7]. Latency and amplitude are measured and determined. Latency measures the time time and measures distance. Amplitude measures the power and is more variable vis a vis latency. Monitoring of dorsal column intactness by SSEP is the commonest form in neurospinal surgery.

Subdermal needle electrodes which are made of Platinum, used for stimulation and recording. Normally, following is considered $50 \%$ decrease in amplitude (b) along with 10\% increase in latency in comparison to baseline values of the patients, makes a warning signal. False negative SSEP monitoring happening during spinal surgery in $0.063 \%$ [8]. Multicenter, very vast, research has concluded the result in reduction of postoperative paraplegia by more than 50\%-60\% with modality [9]. SSEP signals are good indicators of spinal cord function. But much better information about function of nerve root are provided by use of motor evoked potentials.

Direct waves MEP (or spinal motor evoked potentials) these waves are compound corticospinal action potentials started by the direct activation of axons and velocity(conduction) of nearly $50 \mathrm{~m} / \mathrm{s}$ [10], thus making it useful for monitoring the motor pathways up from the motor cortex up to level of the spinal electrode placement. This is gained by single transcranial electrical stimulation of the of intensity by, $80-100 \mathrm{~mA}$, and the total stimulus duration of 0.5-1 ms, using normal frequency of 0.5-2 Hz. Recording of which done from the epidural/ subdural space of cord [11]. This is directly generated electrical pulse and thus called "single stimulus technique" of MEP or "spinal motor evoked potentials (MEPs)". This does not require an averaging, but if few averages are taken it improves quality of MEP. This is also good because it provides real-time reading clinically. Warning sign are the decrease in wave amplitude by or more than 50 percent of original baseline value. Or when they cannot be detectable. This may indicate happening of or high probability of severe neurological deficits which may include injuries such as permanent paraplegia.

Other measurements can be used are

- $\quad$ Neurogenic MEP

- $\quad$ Muscle MEP (or myogenic MEP)

- Spontaneous electromyography

Spontaneous or free-running electromyography (EMG) is used to see or observe selective nerve root functioning undergoing neurospinal- cord spinal surgery. SEP and SSEP data are not real time. but EMG is truly "real-time" data observed from terminal muscles. Spontaneous EMG thus may illuminate operative radiculopathy while spinal instrumentation procedure being done. This also may include pedicle screw putting. Here no stimulation is required. This can be recorded continuously from particular peripheral muscle or muscle groups supplied by particular nerve roots which are at risk during operation [12-18].

Method of triggered EMG for observation of the intactness of lumbar pedicles while doing screw placement surgery and the accuracy screw putting was described in 1922 by Calancie., et al. [19].

There is a decrease in electric threshold leading to immediate appearance of CMAPs of the muscles under consideration by the irritated or damaged nerve root that muscle group due to stimulation using the screw [20].

\section{Spinal cord evoked potentials}

SCEP technique was first described in Japan during 1970s. Electrical stimulation was put on the dorsal spinal cord by epidural electrodes during procedure [21] and evoked potentials are recorded over the spinal cord. The SCEP correspond to total of neural activities that originating from the upgoing and down coming tracts and neurons at the site of recording. The potentials so recorded are quite vigorous. They in reality show all activity of the tracts of the spinal cord, including dorsal columns and the corticospinal tracts along with others ${ }^{22}$. Therefore practically, SCEP cannot provide accurate inputs regarding motor activities. It's so because of presence of sensory-related potentials as well. These sensory potentials, are large in amplitude, and mask motor potentials.

Neurophysiological intra operative graph have been shown as graph 1 and 2.

Citation: PK Upadhyay., et al. "Anterior Cervical Discectomy, Corpectomy with MRI Compatible Titanium Plate and Screw Fixation Under Neurophysiological Monitoring, Experience of 27 Years". Acta Scientific Medical Sciences 6.1 (2022): 320-326. 


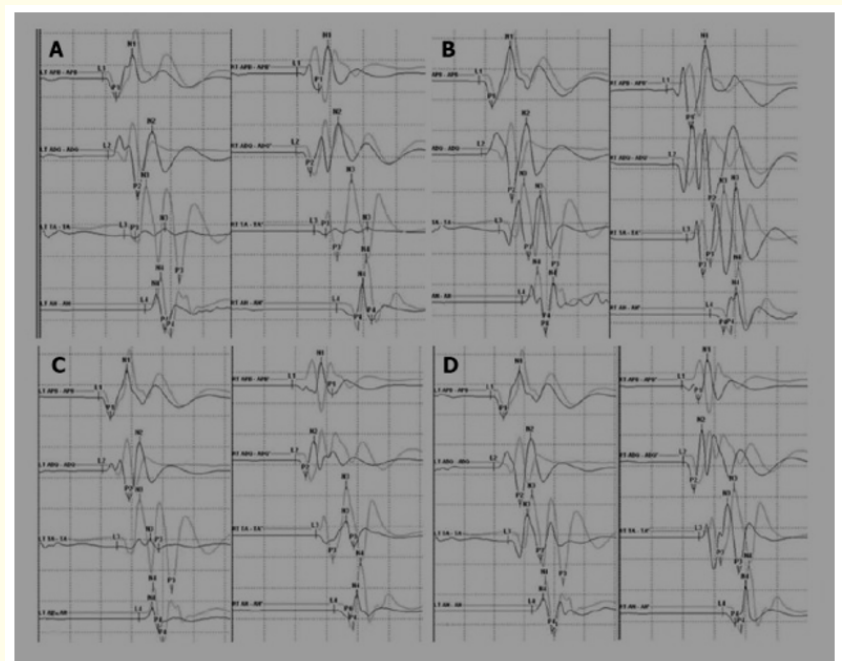

Graph 1: Representative case demonstrating clinical usefulness of intraoperative neuromonitoring in spinal surgery. A: MEP after applying rod to the screw heads using derotation maneuver and cantilever maneuver. The amplitude of MEP (black line) at both lower more than $50 \%$ compared with the baseline amplitude (green line); B: The amplitude of MEP recovered after correction release by removal of the rods and set screws; C: The amplitude of MEP re-deteriorated extremities decreased after reassembly of the implants; D: The amplitude of MEP recovered finally after raising MAP and administration of dexamethasone. APB: Abductor pollicis brevis; ADQ: Abductor digiti quinti; TA: Tibialis anterior; AH: Abductor halluces; MEP: Motor evoked potential; MAP: Mean arterial pressure..

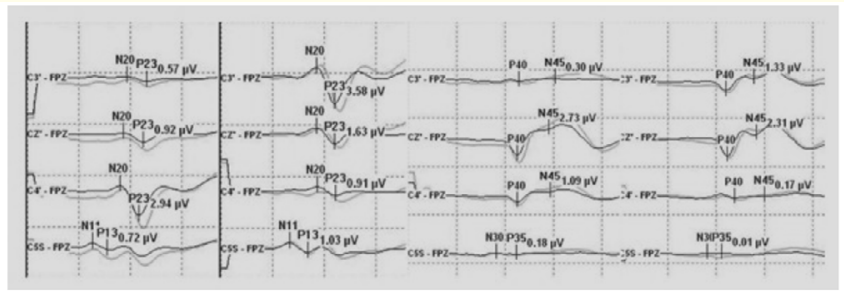

Graph 2: SSEP showing no change in comparison to base line.

\section{Operative procedure}

Standard anterior cervical approach was used. In traumatic cases traction was applied and x-ray were taken to see reducibility. Fracture segment were drilled out along with removal of protruding disc. Cortical plates of superior and inferior vertebral bodies, osteophytes and breaking or compressing portion of body are drilled out and removed.

Tricorticate graft taken from iliac crest was inserted and space left was filed with chips of cancellous bone. Drill holes were made using guide to a constant depth of $14 \mathrm{~mm}$ holes were then tapped. Thereafter plate was fixed using foundation screw which was inserted flushed with the body surface, the locking screw were inserted to lock in the foundation screw.

Post operatively a Philadelphia cervical collar is advised along with antibiotic for a week.

Sutures removed on $7^{\text {th }}$ day. X- Ray were also done on same day. Post operative MRI done only when the case failed to improve satisfactorily.

Post operative x-ray shown in picture 4, 5 .

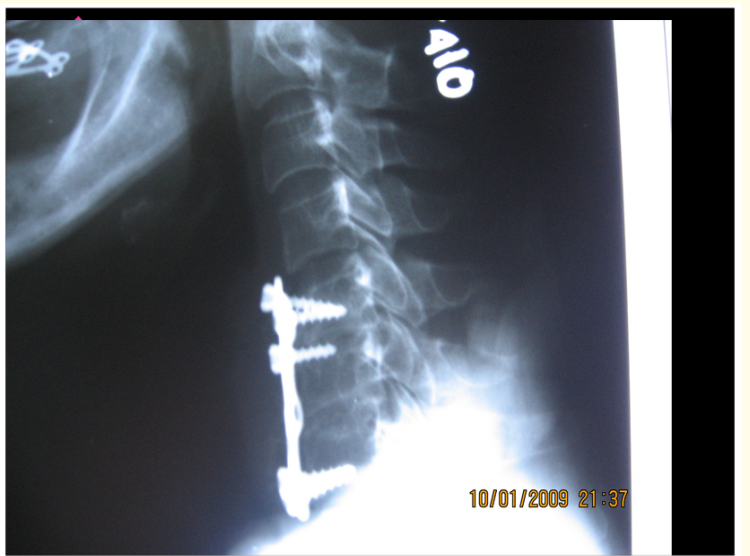

Picture 4: Post operative X- Ray.

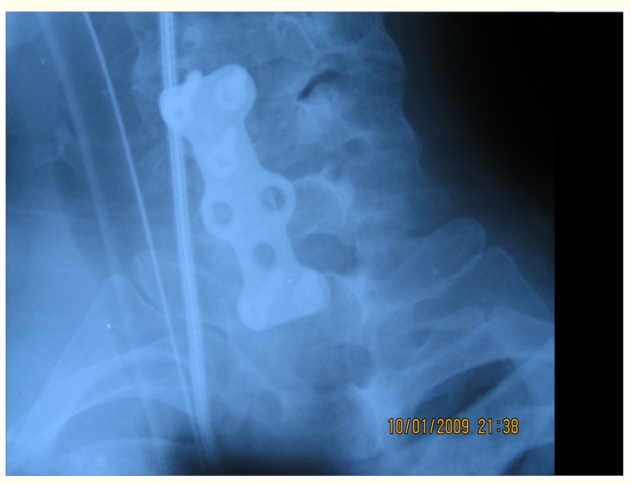

Picture 5: Post operative $x$-ray. 


\section{Results}

Post operative found in 7 cases which responded to appropriate antibiotics. Temporary recurrent nerve paralysis developed in 5 cases which improve within a week. Dysphasia for solid food developed in 2 cases which improved within 10 days.

70 cases performed on C 5/6 level, While 40 case on C 6/7 while 5 cases were performed in 4 cases.

Cases in which cage or peek were used, not included in this study. In two cases there was displacement of screw and plate which required reexploration and refixation with use of bone cement and larger diameter of screws. Both cases had fall.

Postoperative photographs of patient shown in picture 6, 7.

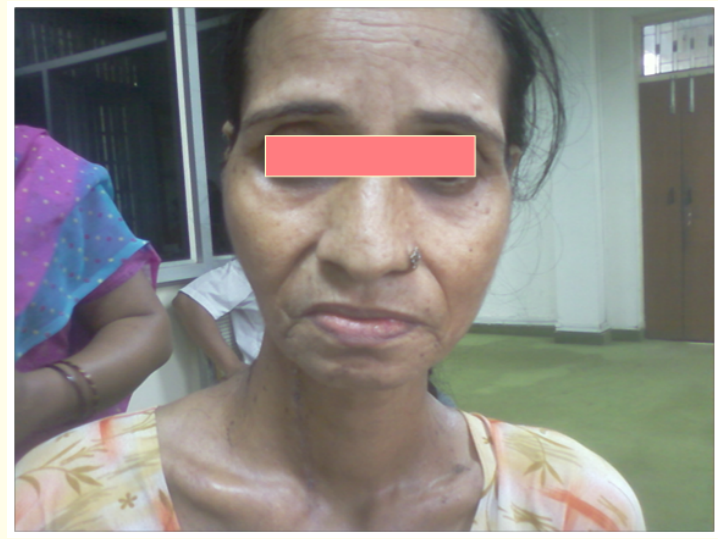

Picture 6: Post operative picture of patient.

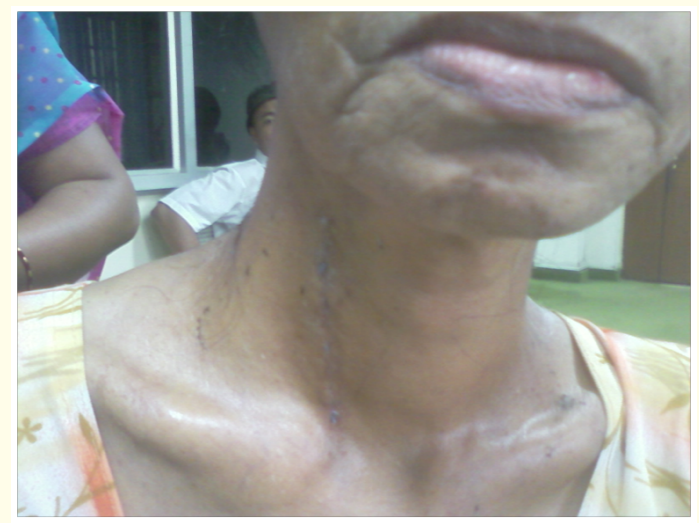

Picture 7: Post operative picture of patient.

\section{Discussion}

Anterior metallic plating for treatment of acute cervical trauma is well established but the indication in degenerative disease were unclear [23-30,32-35,37-39,42].

The excellent outcome for plating in cervical trauma, the immediate stabilization, and theoretical advantages of decreasing graft migration have made the procedure attractive option in degenerative disease $[23,26-31,33,34,36,38,40,41,43]$.

Several studies have shown the superiority of plating over fusion techniques in patients with degenerative cervical spine. It was also shown to have fewer graft extrusion and early return to work in comparison to fusion technique [40].

Caspar and Pitzen reported that graft migration was reduced in multilevel fusion and plating and completely illuminated in single level fixation and plating. They also showed increased fusion rate in anterior cervical plating.

Zdeblick., et al. showed that plating increases the biomedical rigidity and supported their use in traumatic condition but fusion rate was unchanged in their study and therefore they did not support their use in degenerative conditions [43].

Plating also increases surgeons confidence and patient security by using neurophysiological monitoring during surgery and plating increases the stability of the construct, obviate the use of external orthosis, thereby promoting early mobilization and therefore economical. Early mobilization leads to improved pulmonary function and care, decreased incidence of deep venous thrombosis, and other morbidity associated with prolonged immobilization.

In our study patient undergoing plating, returned to usual activity much sooner with decreased rate of complications due to use of neurophysiological monitoring during surgery.

One or two levels of anterior discectomy and fusion with anterior plating for cervical trauma, cervical disc disease and spondylosis and Pott's spine is safe and effective procedure under neurophysiologial monitoring.

\section{Conclusion}

Although we cannot monitor every function of the spinal cord during spinal surgery, the technology of IONPM has markedly de- 
veloped. It is certain that the significance and utilization of IONPM during spinal surgery will increase because of medicolegal issues as well as its usefulness. All neurospinal surgeons should know and understand the principles of the IONPM monitoring. IONPM observations and results of such monitoring records adequately to use for benefit of patients. Thus IONPM observation and results for decision making during the neurosurgery for safe neurosurgery, for favorable surgical outcome and the Neurospinal surgeon's medicolegal and ethical as well as safety of his patients.

Use of Neurophysiological monitoring is safe, infuses confidence of surgeon during surgery and increases security of patients due to decreased injury and complications due to monitoring during surgery. Plating as such takes less time easier to apply and causes less complication as well. Use of neurophysiological monitoring decreases further the chances of complications. Titanium Plating has advantage of being MRI compatible with better fusion rate and does not prevent its use in the future evaluation or reevaluation of those patients.

\section{Bibliography}

1. Alexander ARV., et al. "Anterior plate instrumentation for disorders of cervical spine". Clinical Orthopaedics and Related Research 335 (1997): 112-121.

2. Smith GW and Robinson RA. "The treatment of cervical spine disorder by removing of intervertebral disc and anterior body fusion". Journal of Bone and Joint Surgery 40 (1958): 607-624.

3. Cloward RB. "The anterior approach for the removal of ruptured cervical disc". Journal of Neurosurgery (1958): 1560215617.

4. Michael JR., et al. "The use anterior casper plate fixation in acute cervical spine injury". Surgical Neurology 136 (1991): 181-189.

5. Daniel Ripa., et al. "Series of 92 truamatic cervical spine injuries stabilized with anterior ASIF plate fusion technique". Spine 16.3 (1991) S 46-55.

6. Sala F., et al. "Intraoperative neurophysiology in tethered cord surgery: techniques and results". Child's Nervous System 29 (2013): 1611-1624.

7. Gavaret M., et al. "Intraoperative neurophysiologic monitoring in spine surgery. Developments and state of the art in France in 2011". Orthopaedics and Traumatology: Surgery and Research 99 (2013): S319-S327
8. Nuwer MR., et al. "Somatosensory evoked potential spinal cord monitoring reduces neurologic deficits after scoliosis surgery: results of a large multicenter survey". Electroencephalography and Clinical Neurophysiology 96 (1995): 6-11.

9. Nuwer MR. "Spinal cord monitoring". Muscle and Nerve 22 (1999): 1620-1630.

10. Macdonald DB., et al. "Intraoperative motor evoked potential monitoring - a position statement by the American Society of Neurophysiological Monitoring". Clinical Neurophysiology 124 (2013): 2291-2316.

11. Kothbauer KF. "Intraoperative neurophysiologic monitoring for intramedullary spinal-cord tumor surgery". Neurophysiologie Clinique 37 (2007): 407-414.

12. Owen JH., et al. "Sensitivity and specificity of somatosensory and neurogenic-motor evoked potentials in animals and humans". Spine (Phila Pa 1976) 13 (1988): 1111-1118.

13. Morota N., et al. "The role of motor evoked potentials during surgery for intramedullary spinal cord tumors". Neurosurgery (1997).

14. Kothbauer KF., et al. "Motor-evoked potential monitoring for intramedullary spinal cord tumor surgery: correlation of clinical and neurophysiological data in a series of 100 consecutive procedures". Neurosurgical Focus 4 (1998): e1.

15. Ulkatan S., et al. "Monitoring of scoliosis surgery with epidurally recorded motor evoked potentials (D wave) revealed false results". Clinical Neurophysiology 117 (2006): 2093-2101.

16. Deiner S. "Highlights of anesthetic considerations for intraoperative neuromonitoring". Seminars in Cardiothoracic and Vascular Anesthesia 14 (2010): 51-53.

17. Lall RR., et al. "Intraoperative neurophysiological monitoring in spine surgery: indications, efficacy, and role of the preoperative checklist". Neurosurgical Focus 33 (2012): E10.

18. Gonzalez AA., et al. "Intraoperative neurophysiological monitoring during spine surgery: a review". Neurosurgical Focus 27 (2009): E6.

19. Calancie B., et al. "Intraoperative evoked EMG monitoring in an animal model. A new technique for evaluating pedicle screw placement". Spine (Phila Pa 1976) 17 (1992): 1229-1235.

20. Bosnjak R and Dolenc VV. "Electrical thresholds for biomechanical response in the ankle to direct stimulation of spinal roots L4, L5, and S1. Implications for intraoperative pedicle screw testing". Spine (Phila Pa 1976) 25 (2000): 703-708. 
21. Tamaki T and Kubota S. "History of the development of intraoperative spinal cord monitoring". European Spine Journal 16.2 (2007): S140-S146.

22. Deletis V and Sala F. "Intraoperative neurophysiological monitoring of the spinal cord during spinal cord and spine surgery: a review focus on the corticospinal tracts". Clinical Neurophysiology 119 (2008): 248-264.

23. Aebi M., et al. "Treatment of cervical spine injuries with anterior plating". Spine 16s (1991): 38-s45.

24. Bohler J Gaudermark T. "Anterior plate stabilization for fracture - dislocation of lower cervical spine". The Journal of Trauma and Acute Care Surgery 20: (1980): 203-205.

25. Brown JA., et al. "Cervical stabilization by plate and bone fisio". Spine 13 (1988): 236-239.

26. Casper $\mathrm{W}$ and Piltzen T. "Anterior cervical plating with single and multifusion in degerative disease over treatment or benefit". Pesented at the tenth European congress of Neursurgery 27 (1995).

27. Chochram G. "A primer or orthopaedic biomechanics". New York:Churchill-Livingstone (1982): 190-198.

28. De Oliveira. "Anterior plate fixation of traumatic lesion of lower cervical spine". Spine 2 (1987): 324-329.

29. Garvey TA., et al. "Anterioe decompression structural bone grafting and casper plate stabilization for unstable cervical spine fracture and/or dislocations". Spine 17.10 (1992): S4315.

30. Grubb MR., et al. "Biomechanical evaluation of anterior cervical spine stabilization in a porcine model". Presented at the $20^{\text {th }}$ annual cervical spine research society meeting research, Plam desert, calofornia December 3 (1992).

31. JohnstonFG and Crockard HA. "One stage internal fixation and anterior fusion in complex cervical spinal disorders". Journal of Neurosurgery 82 (1995): 234-238.

32. Jonssson H., et al. "Locking screw -plate fixation of cervical spine fractures with and withoutancilliary posterior plating". Archives of Orthopaedic and Trauma Surgery 111 (1991): 1-12.

33. Lesoin F., et al. "Jomin mthe anterior approach and plates in lower cervical posttraumatic lesion". Surgical Neurology International 21 (1984): 581-587.
34. Lowery GL., et al. "Anterior cervical interbody fusion locked versus non locked plating systems". Tenth annual north American spine society meeting, Washigton, D.D oct 18 (1995).

35. Randle MJ., et al. "The use of anterior Casper plate fixationin acute cervical spine injury". Surgical Neurology International 36 (1991): 181-189.

36. Razak NH., et al. "A-3 years experience with Morscher titanium plates for cervical spine trauma and degerative diseases". Presented at 63 annual meeting of American association.

37. Ripa dr., et al. "Series of 92 traumatic cervical spine injuries stablized with anterior Asif plate fusion techniques". Spine 16L (1991): s46-s55.

38. Schultz K., et al. "Kinematicsof the cervical spine following discectomy and stabilization Spine". 14 (1989): 116-121.

39. Seifert V., et al. "Spondylectomy, microsurgical decompression and osteosynthesis in the treatment of complex disorders of the cervical spine". Acta Neurochirurgica (Wein) 124 (1993): 104-113.

40. Shapiro S. "Bankedfibula and the locking anterior cervical plate in anterior cervical fusionfollowing cervical discectomy". Journal of Neurosurgery 84 (1996): 161-165.

41. Tippets RH. "Anterior cervical fusion with casper instrument system". Neurosurgery 22 (1988): 1008-1013.

42. Tominga T., et al. "Anterior cervical fixation with the titanium lockingscrew plate: a prilimanary report". Surgical Neurology International 42 (1994): 408-413.

43. Zdeblick TA., et al. "Anterior cervical discectomy,fusion and plating". Acomparative Animal Study Pine 14 (1993): 19741983.

\section{Assets from publication with us}

- Prompt Acknowledgement after receiving the article

- Thorough Double blinded peer review

- Rapid Publication

- Issue of Publication Certificate

- High visibility of your Published work

Website: www.actascientific.com/

Submit Article: www.actascientific.com/submission.php

Email us: editor@actascientific.com

Contact uS: +919182824667 